\title{
Research Paper On optimum stratification using mathematical programming approach
}

\section{FAIZAN DANISH AND S.E.H. RIZVI}

See end of the paper for authors' affiliations

Correspondence to :

\section{FAIZAN DANISH}

Division of Statistics and

Computer Science, Faculty of Basic Sciences,

SKUAST-J, Main Campus Chatha, JAMMU (J\&K) INDIA

Email:danishstat@

gmail.com

\section{Paper History :}

Received : 25.05.2017;

Revised : 22.08.2017;

Accepted : 29.08 .2017 Optimum strata width IRJAES/8.2/435-439.
Abstract : Optimum stratification is a technique which results in minimum possible variance of the estimator for the population characteristic under study. The main objective of stratification is to give a better cross-section of the population so as to gain a higher degree of relative precision. The problem of determining optimum strata boundaries (OSB) was pioneered by Dalenius (1950). The problem of obtaining OSB was recently studied by Khan et al. (2009) who formulated the problem as a mathematical programming problem (MPP) by minimizing variance of the estimated population parameter subject to the condition that the sum of the widths of all the strata would be equal to the range of the given distribution under given allocation procedure. In the present investigation the problem of finding OSB has been taken into consideration as the problem of optimum strata width (OSW), using MPP by dynamic programming technique, when the study variable is uniformly distributed. Empirical study has also been taken where it is revealed that with the increase in the number of strata to a fixed number the precision of the method goes on increasing. Also the proposed method proves better than other stratification method (Singh,1967).

KEY Words : Mathematical programming problem, Optimum stratification, Optimum strata boundaries,

How To Cite This Paper : Danish, Faizan and Rizvi, S.E.H. (2017). On optimum stratification using mathematical programming approach. Internat. Res. J. Agric. Eco. \& Stat., 8 (2) : 435-439, DOI : 10.15740/HAS/ 